\title{
AUTORITARISMO Y DEMOCRACIA DE EXCEPCIÓN: EL CONSTITUCIONALISMO DEL ESTADO DE SITIO EN COLOMBIA (1957-1978)*
}

\author{
Jorge Enrique Carvajal Martínez** \\ Andrés Mauricio Guzmán Rincón **
}

Fecha de recepción: 2 de febrero de 2017

Fecha de evaluación: 27 de abril de 2017

Fecha de aprobación: 16 de mayo de 2017

Artículo de reflexión

DOI: http://dx.doi.org/10.18359/prole.3041

Forma de citación: Carvajal, J. E. \& Guzmán, A. M. (2017). Autoritarismo y democracia de excepción: el constitucionalismo del estado de sitio en Colombia (1957-1978). Revista Prolegómenos Derechos y Valores, 20, 40, 63-75. DOI: http://dx.doi.org/10.18359/prole.3041

\section{Resumen}

En el presente artículo se aborda desde un punto de vista histórico y sociojurídico el estudio del estado de sitio en Colombia para el periodo 1957-1978, es decir, el periodo del Frente Nacional y que dio lugar al restablecimiento del régimen constitucional luego del Gobierno de facto liderado por el general Gustavo Rojas Pinilla. El propósito principal es identificar analíticamente las características de la racionalidad que servían a los gobernantes y órganos del Estado para fundamentar su declaratoria y, por otra parte, las tensiones con el concepto clásico de Constitución Política entendida como límite y control del poder político. Se utiliza un método hermenéutico, histórico y crítico para fundamentar la hipótesis que se defiende, la cual gira en torno a la configuración de un régimen de excepción que pretendía legitimación democrática.

\section{Palabras clave:}

Excepcionalidad, Frente Nacional, democracia, Constitución Política de 1886, estado de sitio.

\footnotetext{
Artículo producto de investigación en el marco del proyecto "Democracia y justicia en los sistemas de protección a los derechos humanos" adscrito al Grupo de Investigación Derecho Constitucional, Reforma de la Administración de Justicia y Bloques de Constitucionalidad de la Facultad de Derecho de la Universidad La Gran Colombia (Bogotá, Colombia).

* Doctor en Sociología Jurídica e Instituciones Políticas. Máster en Estudios Políticos del Instituto de Estudios Políticos y Relaciones Internacionales de la Universidad Nacional de Colombia (Bogotá, Colombia). Especialista en Sociología Jurídica de la Universidad Externado de Colombia (Bogotá, Colombia). Abogado de la Universidad Nacional de Colombia y licenciado en Ciencias Sociales de la Universidad Distrital Francisco José de Caldas (Bogotá, Colombia). Profesor asociado de la Facultad de Derecho, Universidad Nacional de Colombia. Docente de la maestría en Derecho, Universidad La Gran Colombia (Bogotá, Colombia). Correo electrónico: jorge.carvajal@ugc.edu.co

** Abogado y magíster en Derecho de la Universidad Nacional de Colombia (Bogotá, Colombia). Profesor de la Facultad de Posgrados de la Escuela Superior de Administración Pública (Bogotá, Colombia) y de la Facultad de Derecho de la Universidad La Gran Colombia (Bogotá, Colombia). Correo electrónico: andres.guzman@ugc.edu.co
} 


\title{
AUTHORITARIANISM AND DEMOCRACY OF EXCEPTION: THE CONSTITUTIONALISM OF THE STATE OF SIEGE IN COLOMBIA (1957 - 1978)
}

\section{Summary}

The hereby article approaches the Colombian state of siege of 1957 - 1978 from a historical and social-legal point of view, during the period well known as the "National Front", which made it possible for the reestablishment of the constitutional regime after the facto government led by General Gustavo Rojas Pinilla. The main purpose of this research was to analytically identify the characteristics of the governors and state rational thinking that helped to support their declaration and on the other hand, supported the tensions with the classic concept of constitution, understood as a limit and control of the political power. The hermeneutic, historical and critical method were used to underlie the supported hypothesis, which revolves around the formation of a regime of exception that sought after democratic legitimation.

\section{Key words:}

Exceptionality, National Front, Democracy, Political Constitution of 1886, State of Siege.

\section{AUTORITARISMO E DEMOCRACIA DE EXCEÇÃO: O CONSTITUCIONALISMO DO ESTADO DE SÍTIO NA COLÔMBIA (1957- 1978)}

\begin{abstract}
Resumo
No presente artigo aborda-se a partir de um ponto de vista histórico e socio-jurídico o estudo do estado de sítio na Colômbia para o período 1957-1978, ou seja, o período do frente nacional e que levou à restauração do governo constitucional depois do Governo de fato liderado pelo General Gustavo Rojas Pinilla. O objetivo principal foi identificar analiticamente as características da racionalidade que servia aos governantes e organismos do Estado para fundamentar a sua declaração e, por outro lado, as tensões com o conceito clássico de constituição política entendida como limite e controle do poder político. Foi utilizado um método hermenêutico, histórico e crítico para fundamentar a hipótese que se defende, a qual gira em torno à configuração de um regime de exceção que buscava legitimidade democrática.
\end{abstract}

\section{Palavras-chave:}

Excepcionalidade, frente nacional, democracia, constituição política de 1886, estado de sítio.

\section{Introducción}

En el presente artículo se aborda desde un punto de vista histórico y sociojurídico el estudio del estado de sitio en Colombia para el periodo 1957-1978, es decir, el periodo del Frente Nacional y que dio lugar al restablecimiento del régimen constitucional luego del Gobierno de facto liderado por el general Gustavo Rojas
Pinilla. El propósito principal es identificar analíticamente las características de la racionalidad que servían a los gobernantes y órganos del Estado para fundamentar su declaratoria y por otra parte, las tensiones con el concepto clásico de Constitución Política entendida como límite y control del poder político. Se utiliza un método hermenéutico, histórico y crítico para fundamentar la hipótesis que se defiende, la 
cual gira en torno a la configuración de un régimen de excepción que pretendía legitimación democrática.

Se efectúa aquí una caracterización del estado de sitio en Colombia de 1957 a 1978, a partir de la reconstrucción del contexto histórico en el que tuvo lugar, abordando el análisis de los aspectos más representativos y las condiciones de racionalidad que servían a los gobernantes y órganos del Estado para basar su declaratoria, advirtiendo de igual manera las tensiones que su desarrollo tuvo con el concepto clásico de Constitución Política, entendida primordialmente como dispositivo de control del poder político y marco institucional de la división de poderes.

Antes de avanzar es importante efectuar algunas precisiones: se hará referencia en concreto a la facultad constitucional de declaratoria de estado de sitio de la que hicieron uso los jefes de Estado durante las décadas de los sesenta, setenta y ochenta. Como toda experiencia histórica, esta alberga sus propias complejidades y particularidades, de forma específica para Colombia vale la pena anotar una transformación frente a la comprensión y desarrollo de esta institución a partir de la instauración del Frente Nacional $^{1}$ en 1957, y el inicio del periodo del expresidente de la república Julio César Turbay Ayala en 1978, fecha a partir de la cual se destacan cambios significativos que van a perdurar aproximadamente hasta el fin del periodo presidencial de Virgilio Barco en 1990. La fecha comprendida entre 1957 y 1978 da cuenta de las peculiaridades de una fase histórica que la diferencia claramente de otras, en las que es posible identificar otras significaciones sobre su sentido y alcance, que se manifestaron también en la transformación de los marcos jurídicos que le daban sustento.

1 Este término alude a la coalición política pactada en el país entre los partidos Liberal y Conservador que se mantuvo vigente entre 1957 y 1974, como mecanismo para superar la dictadura del general Gustavo Rojas Pinilla y la guerra civil que enfrentó a dichos partidos. Su principal rasgo fue el de establecer la alternación en el poder entre representantes de los dos partidos durante esos 16 años, correspondiéndole a cada uno un periodo de 4 años.
La metodología escogida aplica herramientas propias de los estudios jurídicos, por ejemplo se recurre a la interpretación de fallos judiciales paradigmáticos desde la reconstrucción del contexto histórico, para lo cual se consultaron investigaciones relativamente recientes sobre el tema, así como fuentes históricas, frente a la reconstrucción del paradigma constitucional que sirve como referente de evaluación, los autores toman como punto de partida los desarrollos actuales desde una perspectiva de derechos humanos.

Ahora bien, Gustavo Gallón (1979) sostiene que si bien es cierto que desde noviembre de 1948 hasta el 7 de agosto de 1958 el país fue gobernado a través del estado de sitio permanente para regular los asuntos estatales, por parte del dictador Gustavo Rojas Pinilla, este proceder se enmarcaba en los métodos generales de la dictadura militar. En ese sentido, es desde 1958 que se restablecen las instituciones democráticas liberales y los gobiernos recurren de manera persistente a la institución del estado de sitio consagrada constitucionalmente, lo que sin duda caracteriza este periodo histórico y lo distingue del estado de sitio propio de la dictadura militar (Gallón, 1979).

En Colombia a pesar de que la declaratoria de estado de sitio de acuerdo con lo dispuesto en el texto de la Constitución Política de 1886, vigente para la época en estudio, era una facultad excepcional del gobernante, los hechos demuestran que este era un instrumento ordinario de la política interior. Lo que evidencia que hasta 1991 no existiera un control ni político ni jurídico efectivo frente a su declaratoria, que en últimas desvirtuaba su sentido y alcance.

Los autores que investigan el tema, advierten que en el país se ha abusado de la institución de los estados de excepción, que era aún más significativo hasta antes de la expedición de la Constitución Política de 1991 (Ariza, 1997; Gallón, 1979; García, 1993). "En realidad, la utilización constante de las medidas excepcionales, además de desdibujar su propia definición, han 
sustituido a la normalidad institucional colocando a Colombia en el límite entre un Estado democrático y uno autoritario" (Ariza, 1997, p. 7).

Esta situación se hace aún más latente si se tiene en cuenta que numerosas normas adoptadas durante la declaratoria de los estados de sitio han prolongado su vigencia de forma indefinida incluso hasta nuestros días, razón por la cual muchas de ellas se encuentran incorporadas como normas ordinarias (Ariza, 1997; García, 1993).

Uprimny y García (2005) sostienen que desde 1958 hasta 1978 el país vivió 48,5 meses en estado de excepción, esto corresponde al 33,4 $\%$ del periodo. La tabla 1 expone esta cifra, discriminada según los ciclos presidenciales en los que se dio su declaratoria.

Tabla 1. Meses y porcentaje en estado de excepción (1958-1978)

\begin{tabular}{lcc}
\hline \multicolumn{1}{c}{ Presidente } & $\begin{array}{c}\text { No de meses } \\
\text { en estado } \\
\text { de excepción }\end{array}$ & $\begin{array}{c}\text { \% del perio- } \\
\text { do en estado } \\
\text { de excep- } \\
\text { ción }\end{array}$ \\
\hline $\begin{array}{l}\text { Lleras Camargo } \\
\text { (1958-1962) }\end{array}$ & 4 & 8,3 \\
\hline $\begin{array}{l}\text { Valencia } \\
\text { (1962-1966) }\end{array}$ & 14,5 & 30,2 \\
\hline $\begin{array}{l}\text { Lleras Restrepo } \\
\text { (1966-1970) }\end{array}$ & 30 & 62,5 \\
\hline $\begin{array}{l}\text { Pastrana } \\
\text { (1970-1974) }\end{array}$ & 39 & 81,3 \\
\hline López (1974-1978) & 34 & 70,8 \\
\hline
\end{tabular}

Fuente: Uprimny y García (2005).

Para estudiar el periodo señalado, en la primera parte se describen las características jurídicas de la declaratoria de estado de sitio, partiendo del análisis de la Constitución de 1886; y en la segunda se examina el papel que cumplió la Corte Suprema de Justicia en la legitimación de los estados de sitio, al ejercer un control meramente protocolario y fundamentado en tesis que plantean expresamente la facultad discrecional del gobierno para decretarla.
El análisis de cada uno de estos apartados se enriquecerá con una breve referencia histórica de los subperiodos en los que el estado de sitio adquiere ciertas particularidades según la realidad histórica y económica que afrontaron los gobiernos que lo decretaron. Este ejercicio permitirá, siguiendo a Claire (2014), afirmar que "la clasificación de un evento como excepcional, de emergencia o de crisis es un acto de construcción de la realidad y no un hecho demostrable en sí" (Claire, 2014, p. 206).

\section{A. Generalidades del estado de sitio a partir de la Constitución de 1886: aspectos jurídicos de las facultades extraordinarias}

\section{Las amplias facultades excepcionales conferidas al poder ejecutivo antes de 1968}

De acuerdo con lo dispuesto en la Constitución de 1886, el legislador estaba autorizado para dar facultades legales al gobierno durante el estado de sitio: por ejemplo, durante la dictadura del general Gustavo Rojas Pinilla se profiere el decreto legislativo 3418/1954, que consagraba en su artículo 5 que el gobierno podía en estado de sitio "recuperar el dominio pleno de frecuencias o canales de radiodifusión cedidos a particulares para su explotación". Siete años después, es decir, en 1961, mediante la ley 141 de ese mismo año, esa disposición adquirió carácter legal al ser convertida en legislación permanente, de conformidad con lo dispuesto en el artículo 121 de la Constitución Política de 1886 (Gallón, 1979).

Otro ejemplo es el de la facultad dispensada al gobierno para modificar el presupuesto nacional mediante la simple decisión de los ministros, esta atribución la contenía el artículo 104 del decreto-ley 294/1973. Tal decreto se profirió con fundamento en facultades extraordinarias otorgadas por el Congreso y que se conocía en ese momento como el "estatuto orgánico del presupuesto" (Gallón, 1979). 
La Carta de 1886 también contemplaba algunas facultades que se concedían directamente al gobierno durante los estados de sitio, estas eran: (i) retener personas sospechosas tanto tiempo como lo juzgara necesario cuando se encontrara turbado el orden público (art. $28 \mathrm{CN}$ 1886); (ii) en caso de guerra las autoridades no judiciales podían expropiar sin indemnización previa e incluso ocupar la propiedad inmueble, así como usar sus productos para las necesidades de la guerra (art. 33 CN 1886); (iii) la circulación de impreso por correo podía ser prohibida o restringida (art. $38 \mathrm{CN}$ 1886); (iv) la libertad de prensa podía ser suspendida (art. 42 CN 1886); (v) decretar impuestos para restaurar el orden público (art. $43 \mathrm{CN}$ 1886); (vi) concentrar en un solo órgano o persona la autoridad política y civil o la función judicial y militar (art. $61 \mathrm{CN}$ 1886), por ejemplo a través de la creación de "consejos verbales de guerra" recurrentes en el periodo en estudio para juzgar miembros de las fuerzas militares y a la población civil; (vii) el presidente podía dirigir las operaciones de guerra como jefe máximo de los ejércitos (art. 120 , ordinal 8 CN 1886); y (viii) el gobierno podía percibir impuestos u ordenar gastos no contemplados en el presupuesto aprobado por el Congreso de la República (art. 206 CN 1886) (Gallón, 1979).

La declaratoria del estado de sitio se regulaba por el artículo 121 de la Constitución Política de 1886, que a su vez se había mantenido desde la reforma constitucional de 1910. Es importante mencionar que con la reforma de 1968, nuevamente se enmienda dicho artículo 121 y se crea la institución denominada "estado de emergencia económica" con la finalidad de evitar que se recurriera a la declaratoria del estado de sitio, cuando los motivos tenían un claro contenido económico.

De allí que de 1958 a 1968 rigió el artículo 121 constitucional vigente desde 1910, mientras que, de 1968 en adelante, rige una nueva regulación constitucional, razón por la cual se pasa a describir brevemente las características de la regulación atendiendo a esta diferenciación. La tabla 2 muestra las características de la regulación del estado de sitio antes de 1968.

Tabla 2. Estado de sitio en la Constitución de 1886 antes del acto legislativo 01/1968

\section{Disposiciones de la Constitución Política de 1886 frente a la declaratoria del estado de sitio antes de 1968}

Artículo 121: [Modificado por el artículo 33 del acto legislativo 03/1910] "En los casos de guerra exterior, o de conmoción interior, podrá el Presidente, previa audiencia del Consejo de Estado y con la firma de todos los Ministros, declarar turbado el orden público y en Estado de sitio toda la República o parte de ella.

Mediante tal declaración quedará el Presidente investido de las facultades que le confieran las leyes, $\mathrm{y}$, en su defecto, de las que le da el Derecho de gentes, para defender los derechos de la Nación o reprimir el alzamiento. Las medidas extraordinarias o decretos de carácter provisional legislativo que, dentro de dichos límites, dicte el Presidente, serán obligatorios siempre que lleven la firma de todos los Ministros.

\section{Características de la regulación constitucional vigente para esa época}

No existía una diferenciación entre los casos de guerra exterior y conmoción interior, lo que implica que para ambas coyunturas se podía recurrir a la misma medida excepcional de la declaratoria de estado de sitio y la turbación del orden público.

Consagración de una formulación bastante vaga sobre la existencia de una "turbación del orden público" que daba un amplio margen de interpretación que podía ser aprovechado por los gobernantes de turno para abusar de esta figura ${ }^{2}$.

que pueden ser empleadas por los gobernantes para introducir medidas autoritarias o suspender derechos y garantías de orden superior (Carbonell, 2008). 


\section{Disposiciones de la Constitución Política de 1886 frente a la declaratoria del estado de sitio antes de 1968}

El Gobierno declarará restablecido el orden público luego que haya cesado la perturbación o el peligro exterior; y pasará al Congreso una exposición motivada de sus providencias. Serán responsables cualesquiera autoridades por los abusos que hubieren cometido en el ejercicio de facultades extraordinarias".

Artículo 122: "El Presidente de la República o el que en su lugar ejerza el Poder Ejecutivo, es responsable únicamente en los casos siguientes, que definirá la ley:

1. Por actos de violencia o coacción en elecciones;

2. Por actos que impidan la reunión constitucional de las Cámaras Legislativas, o estorben a estas o a las demás Corporaciones o autoridades públicas que establece esta Constitución, el ejercicio de sus funciones; $y$,

\section{Por delitos de alta traición.}

En los dos primeros casos la pena no podrá ser otra que la de destitución, y, si hubiere cesado en el ejercicio de sus funciones el Presidente; la de inhabilitación para ejercer nuevamente la Presidencia.

Ningún acto del Presidente, excepto el de nombramiento o remoción de Ministros, tendrá valor ni fuerza alguna mientras no sea refrendado y comunicado por el Ministro del ramo respectivo, quien por el mismo hecho se constituye responsable".

Fuente: elaboración propia.

En este marco constitucional se dio la declaratoria de estado de sitio durante los dos primeros gobiernos del Frente Nacional, aspecto que a su vez permite identificar dos subperiodos:

El primero, cuya duración fue del 7 de agosto de 1958 al 1 de enero de 1962, tuvo una vida de 3 años, 4 meses y 23 días, y coincide con el periodo presidencial de Alberto Lleras Camargo. En esta época, el gobierno enfrenta la formación de incipientes organizaciones políticas derivadas de los sectores populares y emergen sindicatos. En el plano económico el

3 Sin embargo, la Corte Suprema de Justicia a través de su jurisprudencia fijó algunos límites a la declaratoria del estado de sitio, sin que esto signifique que hubiese efectuado un control estricto de esta facultad excepcional. Por ejemplo, en algunas sentencias planteó que la

\section{Características de la regulación constitucional vigente para esa época}

La formulación imprecisa del "derecho de gentes" hace referencia a los convenios y tratados ratificados por el Estado frente a situaciones de guerra, que inicialmente servirían más para limitar el poder que para conferir potestades. Sin embargo, en el periodo de análisis, estos nunca se reglamentaron ni se emplearon como fundamento del estado de sitio (Gallón, 1979).

No se contempla ningún término temporal para la declaratoria del estado de sitio, razón por la que los gobernantes hacían un uso indiscriminado de la institución, entendiendo que este podía ser indefinido, en la medida en que dependía en exclusiva del restablecimiento del orden turbado tal y como lo disponía el inciso 3 del artículo 121 de la Constitución. Tampoco se prevé un límite temporal de las normas excepcionales dictadas como consecuencia de la declaratoria de estado de sitio ${ }^{3}$.

De acuerdo con el artículo 122, la responsabilidad del gobernante era bastante limitada, ya que se restringía a la coacción o violencia en elecciones, atentar contra el derecho a la libre reunión y deliberación de algunos órganos políticos y la comisión de delitos de alta traición. Por tanto, se observa que no existen previsiones respecto al carácter imperativo e inalienable de los derechos humanos y en consecuencia, su respeto y salvaguarda aun en situaciones excepcionales. Tampoco se destaca una clara diferenciación entre responsabilidad política y jurídica, ni se establecen controles de orden constitucional. país se encuentra endeudado en el exterior y la producción interna está estancada. En el campo, aún hay presencia de bandas organizadas que continúan ejerciendo actos de violencia.

En tal escenario, el estado de sitio se decreta en algunas regiones, las que se consideran más golpeadas por la violencia y que requieren una urgente recuperación económica, aunque a finales de 1958 y de 1961, este se dictamina en todo el territorio nacional, la razón que dio el gobierno, fue la de un inminente peligro por una revuelta militar (Gallón, 1979).

\footnotetext{
declaratoria debería tener una relación estrecha con la turbación del orden público y tender a su restablecimiento, lo que conllevaba que esta debería tener una duración limitada, esto a su vez excluía de antemano su vocación permanente (Gallón, 1979).
} 
El segundo subperiodo corresponde al mandato del expresidente de la república Guillermo León Valencia, que ordena el estado de sitio en 1963 por siete días, en principio solo en algunas regiones petroleras y con la finalidad de contrarrestar un paro cívico. Sin embargo, el 21 de mayo de 1965, se declara el estado de sitio en todo el territorio nacional hasta el 16 de diciembre de 1968. El objetivo principal que cumplió este instrumento fue el de combatir a los movimientos populares, en particular a los que provenían de la clase obrera y estudiantil que se organizaban en las zonas urbanas.

Este estado de sitio también se aprovecha para adoptar medidas económicas y fiscales, frente a una situación deficitaria de la balanza de pagos, la ausencia de divisas para pagar la deuda externa y la crisis fiscal del Estado (Gallón, 1979).

\section{La reforma constitucional de 1968 y el perfeccionamiento del estado de sitio como instrumento represivo}

Como se advirtió, a partir de 1968 hay una reforma constitucional que incorpora nuevos requisitos para la declaratoria del estado de sitio; a pesar de que se contemplan mecanismos de control judicial y se busca que su declaratoria no sea permanente -así como que esta tenga relación directa con los hechos que le dan origen-, en esencia, no agregó grandes innovaciones, ni hubo un control efectivo del poder judicial respecto al gobierno desde este año hasta 1978. Antes de demostrar esto, en la tabla 3 se destacan las principales innovaciones en la regulación jurídica constitucional.

Tabla 3. Estados de excepción en el acto legislativo 01/1968

\section{Estados de excepción a partir de la reforma constitucional de 1968 . Acto legislativo 01/1968}

Artículo 42: "El Artículo 121 de la Constitución Nacional quedará así: En caso de guerra exterior o de conmoción interior podrá el Presidente, con la firma de todos los Ministros, declarar turbado el orden público y en estado de sitio toda la República o parte de ella. Mediante tal declaración, el Gobierno tendrá, además de las facultades legales, las que la Constitución autoriza para tiempos de guerra o de perturbación del orden público y las que, conforme a las reglas aceptadas por el Derecho de Gentes, rigen para la guerra entre naciones.

\section{[...]}

El Gobierno no puede derogar las leyes por medio de los expresados decretos. Sus facultades se limitan a la suspensión de las que sean incompatibles con el estado de sitio.

La existencia del estado de sitio en ningún caso impide el funcionamiento normal del Congreso. Por consiguiente, este se reunirá por derecho propio durante las sesiones ordinarias y en extraordinarias cuando el Gobierno lo convoque.

\section{[...]}

El Gobierno declarará restablecido el orden público tan pronto como haya cesado la guerra exterior o terminado la conmoción interior y dejarán de regir los decretos de carácter extraordinario que haya dictado.

\section{Características de la regulación constitucional}

Esta norma consagra explícitamente que durante los estados de excepción no se podrá clausurar el Congreso.

Estos decretos tienen un control automático por parte de la Corte Suprema de Justicia, cualquier ciudadano podía defender o impugnar su constitucionalidad ante este tribunal.

Establece un régimen distinto y especial para la declaratoria del estado de emergencia económica y social, en la norma anterior se empleaba la fórmula de "turbación del orden público" por razones económicas.

A diferencia de la declaratoria de los estados de sitio, faculta al gobierno a dictar decretos con fuerza de ley de carácter permanente, mientras que los primeros son provisionales.

El gobierno solo tiene facultad para expedir decretos sobre las materias que tengan vínculo directo y específico con la situación de emergencia económica.

El control político recae en el Congreso y este órgano dispone de la facultad de derogar, modificar o adicionar las materias de estos decretos por iniciativa propia y en cualquier momento.

El gobierno y los ministros son responsables por el abuso de estas facultades, o la decreten sin fundamento. 


\section{Estados de excepción a partir de la reforma constitucional de 1968. Acto legislativo 01/1968 \\ Características de la regulación constitucional}

Serán responsables el Presidente y los Ministros cuando declaren turbado el orden público sin haber ocurrido el caso de guerra exterior o de conmoción interior; y lo serán también, lo mismo que los demás funcionarios, por cualquier abuso $[\ldots]$.

Parágrafo. El Gobierno enviará a la Corte Suprema de Justicia el día siguiente a su expedición, los decretos legislativos que dicte en uso de las facultades a que se refiere este Artículo, para que aquella decida definitivamente sobre su constitucionalidad [...]".

Artículo 43: "El Artículo 122 de la Constitución Nacional quedará así: Cuando sobrevengan hechos distintos de los previstos en el Artículo 121, que perturben o amenacen perturbar en forma grave e inminente el orden económico o social del país o que constituyan también grave calamidad pública, podrá el Presidente, con la firma de todos los Ministros, declarar el estado de emergencia por períodos que sumados no podrán exceder de noventa días al año.

\section{$[\ldots]$}

El Congreso podrá en todo tiempo y a iniciativa propia, derogar, modificar o adicionar las materias específicas de los decretos a que se refiere este Artículo.

Serán responsables el Presidente y los Ministros cuando declaren el estado de emergencia sin haber ocurrido los hechos a que se refiere el inciso 1o; lo serán también por cualquier abuso que hubieren cometido [...].

Durante el estado de emergencia económica el Gobierno no podrá desmejorar los derechos sociales de los trabajadores consagrados en leyes anteriores.

Parágrafo. El Gobierno enviará a la Corte Suprema de Justicia el día siguiente a su expedición, los decretos legislativos que dicte en uso de las facultades a que se refiere este Artículo, para que aquella decida definitivamente sobre su constitucionalidad [...]".

Fuente: elaboración propia.

A partir de esta reforma constitucional se cuentan tres subperiodos que dan cuenta de la aplicación del estado de sitio:

El primero de ellos se inaugura el 9 de octubre de 1969 (último año de gobierno del expresidente Carlos Lleras Restrepo) y los tres primeros meses del gobierno de Misael Pastrana (17 de noviembre de 1970). Desde 1968 el estado de sitio va utilizarse exclusivamente como instrumento represivo del gobierno, ya que se adopta una nueva institución que se denomina "estado de emergencia", que cumplirá una finalidad exclusiva para enfrentar los desafíos de la crisis económica.

El estado de sitio se decreta regionalmente en el Valle del Cauca y por ciertos periodos, 
mientras que durante 1970, se amplía hacia todo el territorio nacional, este tiene una duración de tres meses. Como dispositivo represivo del movimiento social, el estado de sitio limita el derecho de reunión y asociación, y mantiene la facultad de los militares para juzgar civiles. En el ámbito económico, la producción interna incrementó de forma considerable gracias a las medidas económicas adoptadas por el gobierno de Carlos Lleras desde 1965 (Gallón, 1979).

El periodo siguiente coincide con la declaratoria del estado de sitio por parte de Misael Pastrana desde el 26 de febrero de 1971 hasta el 29 de diciembre de 1973, en el que se destaca su uso como medida represiva a todo tipo de protesta o reivindicación popular, lo que sin duda afectó gravemente a las organizaciones estudiantiles (Gallón, 1979).

El último subperiodo que va del 12 de junio de 1975 y durante 1976, coincide con el gobierno del exmandatario Alfonso López Michelsen. Este también se sirve del estado de emergencia económica y continúa usando el estado de sitio como arma represiva contra las manifestaciones políticas de oposición de origen popular, campesino y del sector educativo.

En esta época, la finalidad del estado de sitio era primordialmente reprimir a los movimientos populares en las aglomeraciones urbanas y zonas industrializadas. Por tal razón se prohíben las reuniones públicas y las huelgas. Aunque también se empleó como mecanismo de legitimación del gobierno, rodeando de garantías la represión que ejercía, ya que por ejemplo, este se justificaba en la "defensa de las instituciones", símbolo de la unidad nacional, a la vez que se descalifica como "subversivas" las reivindicaciones populares, además el levantamiento del estado de sitio se mostraba como un acto de triunfo del gobierno, que permitía difundir una imagen distorsionada con la cual se defendía que en el país regía la democracia y no el autoritarismo (Gallón, 1979).

Para Gallón (1979) el estado de sitio es un aparato que utiliza todo el Estado y no solo el gobierno, ya que los demás poderes han manifestado su apoyo y legitimación permanente. Lo que a su vez evidencia la enorme influencia de los militares en la configuración del poder político del Estado para esta época, pues han logrado transferir el poder político y jurídico hacia ellos a través de cortes marciales. En últimas, se convierte en una herramienta de control político por parte de las clases dominantes que supera la combatividad de los sectores desposeídos, esto se observa en la desproporcionalidad existente entre las manifestaciones populares y la creciente institucionalidad creada por el Estado con el pretexto de contrarrestarla.

En relación con el periodo 1957-1978, es posible afirmar que hubo un aumento significativo de las protestas ciudadanas ante el descontento político que exteriorizaban algunos sectores sociales, en ese sentido la declaratoria de estado de sitio sirvió con frecuencia a los gobernantes para neutralizar estas manifestaciones y por otra parte, enfrentar la crisis económica que tiene sus orígenes en La Violencia, anterior a este periodo. En el campo se combatía a la insurgencia a través de la confrontación armada y la justicia de excepción, mientras que en la ciudad se restringían los derechos ciudadanos para reprimir las expresiones políticas (García, 1993).

\section{B. El poder judicial frente al poder excepcional}

Hasta la expedición de la Constitución Política de 1991, la Corte Suprema de Justicia era el organismo responsable de asumir las funciones de máximo tribunal constitucional. Durante el periodo que comprende el Frente Nacional a partir de 1958 y hasta 1980, esta ejerce formalmente el control de los decretos expedidos por el gobierno en desarrollo de la declaratoria de estado de sitio. En particular esta etapa se caracterizó por un control bastante débil y casi nominal, en el que las decisiones del poder judicial servían para respaldar al gobierno y legitimar ante la ciudadanía la existencia de 
un poder discrecional por parte de este que no era susceptible de ser limitado mediante mecanismos jurídicos.

En este periodo la Corte Suprema, a través de sus fallos, avaló las medidas excepcionales establecidas por los gobernantes para afrontar la perturbación del orden, ocasionada según la declaratoria del estado de sitio por las protestas estudiantiles, los alzamientos de los trabajadores y posteriormente algunos hechos terroristas. Así por ejemplo, la Corte Suprema de Justicia frente al decreto 1131/1970 que de manera expresa prohibía el derecho de reunión, al proscribir la conformación de grupos de más de tres personas en lugares donde se prestaran servicios públicos, determinó que era una medida constitucional, con el argumento de que la limitación a este derecho era razonable con el propósito de controlar el orden público (Ariza, 1997; Corte Suprema de Justicia, 1970).

La Corte Suprema de Justicia por medio de sus fallos también aceptaba que los civiles fueran juzgados por militares, en el entendido de que este mecanismo permitía una mayor celeridad de la justicia penal militar y que esto redundaría en el restablecimiento del orden público (Corte Suprema de Justicia, 1970). De un argumento similar se valió este alto tribunal para declarar la constitucionalidad del denominado estatuto de seguridad, un decreto en el que se vulneraban de forma palmaria derechos individuales, en especial en materia penal al consagrar la creación de tipos penales, aumentar las penas y tipificar arrestos inconmutables por periodos extensos (Corte Suprema de Justicia, 1978).

La permisividad mostrada por la Corte Suprema respecto a las medidas excepcionales, se mantuvo aproximadamente hasta 1987, época en la que la administración de justicia exterioriza un compromiso por estudiar y entender con mayor rigurosidad estas medidas excepcionales, mientras que, a partir de 1992 con la creación de la Corte Constitucional, se continúa en la línea de evitar y superar dicha permisividad propia de este periodo (Ariza, 1997).
El estatuto de seguridad de 1978 se instaura desde el primer mes de gobierno del expresidente Turbay Ayala, precisamente como una norma que surge de la declaratoria del estado de sitio. Este instrumento hacía posible que los militares arrestaran, interrogaran, torturaran y juzgaran a civiles, teniendo una clara orientación hacia la represión de los movimientos políticos que surgían en las zonas urbanas. La iglesia y algunas ONG denunciaron en su momento el uso de tácticas que vulneraban los derechos humanos por parte de los militares, tales como choques eléctricos, baños con agua fría, submarinos y otros procedimientos de tortura contra civiles en aplicación del estatuto de seguridad (Niño, 1981).

Así las cosas, el control de constitucionalidad de la declaratoria de estados de excepción efectuado por la Corte Suprema de Justicia, se circunscribía a un examen meramente formal que no incluía alguna valoración en torno a los argumentos brindados por el gobierno para la declaratoria del estado de sitio, de esta forma solo se verificaba el cumplimiento de las solemnidades establecidas en la Constitución.

\section{Excepcionalidad a través de la declaratoria de emergencia económica}

En esa vía por ejemplo a través de la sentencia mediante la cual se efectuó el juicio de constitucionalidad del decreto legislativo 1970/1974, y con el que se declaraba por primera vez desde su consagración constitucional en 1968, el estado de emergencia económica; la Corte Suprema de Justicia determinó que la revisión de este tipo de decretos no comprendía los motivos que hubiese tenido en cuenta el gobierno y sus ministros para decretarlo, ya que esta era una decisión potestativa y discrecional.

El Decreto inicial que declara el estado de emergencia económica es un acto conjunto del jefe de Estado y los Ministros, sometido al control de la Corte, en los términos del Art. 214 y del Parágrafo del artículo 122, y cuya revisión no puede comprender el 
estudio de los motivos que se hayan tenido para declararlo, pues tomar esta decisión es potestativa del gobierno, de modo discrecional (Corte Suprema de Justicia, 1974).

Así se entendía que ni siquiera la Constitución Política misma podía limitar la facultad discrecional de la que gozaba el gobernante. Incluso algunos de los magistrados sostenían la naturaleza eminentemente política de este acto y en consecuencia mantenían que le era vedado a los jueces ejecutar cualquier examen al respecto. Por ende, consideraban que el único que podía hacer este juicio era el Congreso de la República. Se entendía además que, si los jueces efectuaban algún control, estarían usurpando la competencia exclusiva del gobierno en relación con asumir la dirección del orden público.

A su vez, esta tesis la compartía el gobierno en cabeza del expresidente de la república Alfonso López Michelsen, quien en el informe presentado sobre la constitucionalidad de la emergencia económica al Congreso Nacional expone lo siguiente:

Siempre consideró el gobierno que la declaratoria de emergencia es un acto potestativo del propio gobierno; que de manera exclusiva pertenece a su competencia. La declaratoria de emergencia en sí misma, el momento en que se produce, la valoración de la situación de hecho que se invoca como causal, y el término durante el cual se van a usar las facultades extraordinarias, que concede, son determinaciones que soberanamente corresponden al gobierno (Daza y Ferraro, 1976, p. 56).

Los estados de excepción que a partir de 1968 incluyen la declaratoria de emergencia económica, profundizaron las facultades del poder ejecutivo y acentuaron prácticamente su carácter ilimitado, esta tesis no solo la acogía el poder judicial sino incluso el Congreso de la República. Así por ejemplo, si bien es cierto que el artículo 122 fijaba un control político sobre la declaratoria de la emergencia económica y los decretos en desarrollo de esta, en su momento el Congreso de la República no hizo uso de esa facultad, y en consecuencia ni objetó ni modificó estas normas con vocación permanente (Daza y Ferraro, 1976) que en total fueron 23. Esto se explica en buena medida porque dos terceras partes del Congreso estaban integradas por partidarios del entonces presidente López Michelsen.

Volviendo a la sentencia antes citada y en la que de modo expreso se defiende el carácter intangible de la declaratoria del poder excepcional por parte del presidente de la república, puede observarse un voto disidente de gran relevancia, suscrito por el entonces magistrado Luis Sarmiento Buitrago, quien se opuso a la tesis dominante y planteó por primera vez en el seno de la Corte Suprema de Justicia que los actos proferidos por el gobernante en uso de la facultad extraordinaria, tenían naturaleza legislativa y por tanto, sobre estos debía haber un control jurídico que se fundamentara en la Constitución y en la ley.

A renglón seguido sostuvo "la invocación a actos de poder discrecionales del presidente es un recuerdo obsoleto del absolutismo monárquico que la democracia ha hecho desaparecer. Si el artículo 122 exige motivar la declaración de emergencia, no es un acto discrecional" (Corte Suprema de Justicia, 1974). Esta tesis que en su momento era minoritaria, se retomó 18 años después por la Corte Constitucional, ya en vigencia de la Constitución de 1991 para defender la idea de un control formal y material de la declaratoria de los estados de excepción.

En cuanto al control de constitucionalidad de estos actos, el magistrado Sarmiento Buitrago arguyó: "El control debe ser en consecuencia integral o no tiene razón de existir. La competencia tiene que ser por aspectos de forma y fondo, o la guarda de la Constitución no es integral" (Corte Suprema de Justicia, 1974). En específico frente a los motivos de la declaratoria de emergencia económica, Sarmiento Buitrago aseguró que esta no estaba justificada en razón del acontecer de una situación anómala: 
Los tres propósitos [lucha contra la inflación y carestía, protección de ingresos y salarios y eliminación de subsidios] corresponden a males crónicos de la economía de la vida colombiana, son hechos que conforman la situación de subdesarrollo del país que bien pueden afirmarse aparejan una situación de normalidad que en manera alguna encaja dentro de los propuestos constitucionales para decretar el estado de emergencia (Corte Suprema de Justicia, 1974).

\section{Conclusiones}

El uso recurrente del estado de sitio en Colombia durante el periodo 1958-1978 evidencia claramente la forma en que el poder político estatal en cabeza del gobierno, logra en ese momento compatibilizar el autoritarismo con un sistema democrático. Lo que en la práctica termina desvirtuando la excepcionalidad al erigirla como norma permanente y vacía la democracia, al convertirla en un referente de legitimación de la represión oficial ante las demandas políticas de los sectores sociales que emergían en ese entonces y que se encontraban inconformes ante el gran déficit de participación y hermetismo propiciado por el Frente Nacional.

En esa medida, este periodo se caracteriza por hacer un uso de esta institución dentro del margen constitucional establecido para tal fin y por ende, se diferencia del periodo inmediatamente anterior en el que la fórmula del estado de sitio se basaba en el poder de facto de la dictadura militar liderada por el general Gustavo Rojas Pinilla. Por eso, podría decirse que el estado de sitio sirve como dispositivo de represión por parte del Estado y a su vez como forma de legitimación del poder autoritario.

Hasta antes de 1968 podría decirse que el estado de sitio era una institución incipiente, que mantuvo unos objetivos claros como enfrentar el surgimiento de organizaciones políticas populares y sindicales en las zonas urbanas y asegurar al estamento militar un lugar privilegiado en la estructura del Estado al permitirle cooptar funciones políticas, administrativas y judiciales, por ejemplo, a través de cortes marciales con competencia para juzgar civiles.

Sin embargo, a partir de la reforma constitucional de 1968, el estado de sitio se perfecciona de manera predominante como instrumento represivo, afectando de forma significativa a las organizaciones obreras y estudiantiles. Mientras que, mediante la declaratoria de emergencia económica, se utiliza un mecanismo excepcional para introducir al país en las exigencias de la economía mundial y enfrentar fenómenos como el déficit fiscal, crisis en la balanza de pagos e implementar medidas de choque en el contexto de la sustitución de importaciones; en ese sentido la transformación del Estado también se efectuó recurriendo a recetas no democráticas.

El estudio de la jurisprudencia proferida por la Corte Suprema de Justicia en este periodo, en relación con el control de constitucionalidad frente a la facultad de los gobernantes de declarar el estado de sitio, prueba que este era una herramienta del Estado para cumplir con esas finalidades de represión y legitimación y en esa medida no solo involucraba al gobierno. El poder judicial construyó y defendió argumentaciones basadas en la ley para justificar el uso de poderes discrecionales por parte del gobernante y negar y rechazar explícitamente su control y limitación.

De forma similar, al menos a finales de los años setenta, se observa que el Congreso tampoco ejerció un contrapeso a la declaratoria de los estados de excepción, a pesar de tener la función de desempeñar un control político, por el contrario, su permisividad hizo que las normas excepcionales tuvieran vocación de permanencia.

\section{Referencias}

Ariza, L. J. (1997). Estados de excepción y razón de Estado en Colombia. Bogotá: Universidad de los Andes.

Carbonell, M. (2008). Neoconstitucionalismo y derechos fundamentales en tiempos de 
emergencia. Estudios Constitucionales, 6(1), pp. 249-263.

Claire, W. (enero-junio de 2014). Poderes de emergencia y regímenes de excepción en América Latina: una perspectiva política. Revista Mexicana de Análisis Político y Administración Pública, III(1), pp. 205-230.

Corte Suprema de Justicia. (1970). Revisión del decreto 1129 de 1970, 13 de agosto.

Corte Suprema de Justicia. (1970). Revisión del decreto 1133 de 1970, 13 de agosto.

Corte Suprema de Justicia. (1978). Revisión del decreto 1923 de 1978, 30 de octubre.

Daza, M. B. \& Ferraro, M. (1976). Efectos y alcances de la primera aplicación de emergencia económica, artículo 122 de la Constitución Nacional. Bogotá:
Universidad Colegio Mayor de Nuestra Señora del Rosario.

Gallón, G. (1979). Quince años de estado de sitio en Colombia. Bogotá: América Latina.

García, M. (1993). La eficacia simbólica del derecho. Examen de situaciones colombianas. Bogotá: Uniandes.

Niño, G. A. (1981). Algunos conceptos sobre el estatuto de seguridad. Bogotá: Pontificia Universidad Javeriana.

Uprimny, R. \& García, M. (2005). ¿Controlando la excepcionalidad permanente en Colombia? Una defensa prudente del control judicial de los estados de excepción. Bogotá: Documentos de Discusión DJS. 